\title{
Lepadarq
}
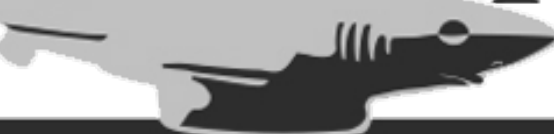

\section{COMERCIANTES, ESPÍAS Y BAQUIANOS: LOS ESCLAVOS CRIOLLOS DEL}

ESEQUIBO COLONIAL. SEGUNDA MITAD DEL SIGLO XVIII

MERCHANTS, SPIES AND "BAQUIANOS": CREOLE SLAVES OF COLONIAL ESSEQUIBO. SECOND HALF OF THE 18TH CENTURY

Karina Estraño

Como citar este artigo:

ESTRAÑO, Karina. Comerciantes, espías y baquianos: los esclavos criollos del Esequibo colonial. Segunda mitad del siglo XVIII. Cadernos do Lepaarq, v. XVII, n.33., p. 150-162, Jan-Jun. 2020. 


\section{Comerciantes, espías y baquianos: los esclavos criollos del Esequibo colonial. Segunda mitad del siglo XVIII}

Resumen: Se exploran las estrategias de negociación y resistencia de los esclavos criollos, "sujetos históricos" de la Guayana holandesa que jugaron un rol clave como agentes de inteligencia, comerciantes bilingües y baquianos; se explora también su participación en las redes políticas y de intercambio comercial de la región fronteriza entre las antiguas Guayanas españolay holandesa, durante la segunda mitad del siglo XVIII.

\author{
Karina Estraño ${ }^{\mathrm{a}}$
}

\section{Palabras Clave:}

Guianas, Esequibo, Afroindianidad, Escravos crioulos, Antropologia Histórica.

\begin{abstract}
I deal with the negotiating and resistance strategies of the creole slaves, "historical subjects" of the Dutch Guyana, which played a key role as intelligence agents, bilingual traders and "baquianos"; also, I explore the political and trading networks of the border region between the Spanish and Dutch Guyanas, during the second half of the 18th century.
\end{abstract}

\section{Keywords:}

Guianas, Essequibo, Afroindigenousness, Creole Slaves, Historical Anthropology.

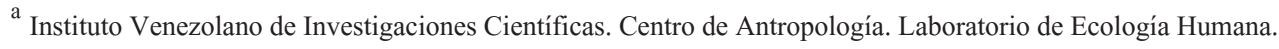




\section{INTRODUCCIÓN}

En la antropología histórica existe un extenso trabajo sobre la etnogénesis de sociedades y culturas afroamericanas en las regiones fronterizas de las Guayanas ${ }^{1}$. En ellos se resaltan al menos cuatro aspectos que marcaron la vida de los africanos y sus descendientes en aquellos territorios: en primer lugar, las particulares condiciones ecológicas y geográficas de la región amazónica. Esta región se caracteriza principalmente por un bosque tropical húmedo con vegetación muy densa y temperatura propicia para la dispersión de enfermedades, como las que durante la expansión europea fueron traídas del viejo continente y África, como el paludismo y la fiebre amarilla. Estas condiciones hicieron casi imposible el avance de los europeos, más allá de las zonas costeras. En segundo lugar, una extensa red radicular de ríos, rápidos y saltos cuya navegación, especialmente durante las primeras etapas del contacto, dependía del conocimiento y habilidades de los indígenas de la región. En tercer lugar, la formación a partir de los procesos de colonización de "zonas de frontera" entre colonias vecinas. Las administraciones imperiales de aquellas colonias pasaron por frecuentes guerras seguidas de períodos de paz, que no siempre eran conocidos en las zonas coloniales. Y por último la existencia, al momento del contacto de múltiples grupos indígenas que mantenían extensas redes de intercambio comercial. Las relaciones y vínculos que se formaron entre indígenas y europeos variaron dependiendo de las estrategias de conquista y colonización, así como de los intereses comerciales de las distintas potencias que se instalaron en la región guayanesa.

La bibliografía sobre la región ofrece estudios históricos y culturales de los grupos afroamericanos que se formaron en las Guayanas y en esas zonas de "frontera". Al respecto, resultan de particular interés los trabajos sobre las sociedades cimarronas de Surinam (PRICE, 2011; 1991; 1990; 1983), y los procesos étnicos que se formaron en los territorios vecinos de las Guayanas francesa, portuguesa y holandesa (GOMES, 2015; 2011; 2003). En conjunto, estas etnografías y trabajos históricos permiten aprehender las distintas formas de resistencia que desplegaron los africanos y sus descendientes, así como la complejidad de las relaciones interénicas en aquellos contextos multiétnicos y multiculturales. Por otro lado, los estudios de Alvin Thompson (2015; 2006; 1999) sobre los cimarrones de la actual región de Guyana describen las particulares condiciones de las colonias holandesas que durante los siglos XVI al XVIII formaron asentamientos vecinos a la Guayana española. Sin embargo, la información que ofrece Thompson sobre los procesos de cimarronaje entre las dos colonias vecinas resultan muy escasos. $Y$ en general esta información permanece dispersa en los archivos coloniales. Por todo ello, el artículo que presentamos a continuación ofrece un aporte a esta área de conocimiento, a partir de fuentes históricas secundarias que reflejan los procesos de intercambio comercial, las luchas territoriales y las cambiantes alianzas políticas entre

\footnotetext{
1 Nos referiremos a las Guayanas como el territorio que actualmente forman los países de Guyana y Surinam (Guayana holandesa), la Guayana Francesa, la región correspondiente a la Guayana Brasilera y la Guayana venezolana, formada por los actuales estados Delta Amacuro, Amazonas y Bolívar. Asimismo, cuando hablamos de Guayana, la Guayana española o la Guayana venezolana, nos referiremos a los actuales estados Delta Amacuro, Amazonas y Bolívar.
} 
europeos, indígenas y afrodescendientes, en el territorio de frontera entre las antiguas colonias de Esequibo y Demerara, y la provincia de Guayana, durante la segunda mitad del siglo XVIII. Es decir, los territorios que hoy forman la República Cooperativa de Guyana, pero especialmente la zona en reclamación con Venezuela, conocida como El Esequibo².

\section{Redes subalternas entre las Guayanas española y holandesa del siglo XVIII}

Cuando hablamos de frontera nos referimos a dos acepciones de esta categoría conceptual: en primer lugar, una separación geopolítica impuesta por la lógica de apropiación y control del territorio por parte de grupos poderosos, en este caso potencias imperiales que durante el período colonial establecieron límites, cuya movilidad y ambigüedad aumentaba, a medida que se alejaban de los centros de administración colonial. En segundo lugar, nos referimos a territorios alejados de la lógica de los centros de administración colonial, donde se formaron procesos sociales y culturales propios y en esa medida se convirtieron en regiones de frontera, $o$ áreas de extrema movilidad humana al margen de la civilización (TURNER, 1953). Nuestra exploración gira en torno a la vida y relaciones políticas que formaron los distintos actores que se establecieron en la región de frontera entre las Guayanas española y holandesa. Al respecto, los trabajos de Neil Whitehead (1992; 1988) nos ofrecen un amplio análisis sobre las redes comerciales indígenas que operaban en aquella extensa región, así como de las distintas relaciones comerciales, alianzas militares y confrontaciones bélicas que se formaron entre españoles y holandeses, y los procesos de etnogénesis y tribalización experiementados por los indígenas, como consecuencia del contacto con los europeos.

Adicionalmente Whitehead (1992; 1998) arroja pistas sobre la participación de afroescendientes en aquellas redes coloniales, y al mismo tiempo permite ver que la presencia de los esclavos negros y cimarrones era escasa en la región. Al respecto, los documentos históricos de la época reflejan que tanto en la provincia de Guayana como en las colonias de Esequibo y Demerara el traslado forzado de esclavizados africanos no fue significativo (BRITO, 1996; 1993; RODWAY, 1981) y ya veremos por qué. En el lado español, por casi tres siglos la provincia de Guayana fue un territorio de escaso interés para los conquistadores y colonos, que centraron su atención primero en la extracción de perlas y después en el desarrollo de plantaciones, en la región norte costera de Venezuela. Asimismo, los pequeños asentamientos que se instalaron en lo que hoy forma el territorio guyanés también ocuparon un lugar secundario para el gobierno colonial holandés. Aquellas tierras estuvieron bajo la administración de la Compañía Holandesa de las Indias Occidentales (WIC por sus siglas en inglés), cuyo interés se centró en el comercio de esclavizados africanos hacia colonias vecinas. Esto marcó una notable diferencia con la administración vecina de Surinam, que se formó por alianzas entre empresarios privados orientados hacia el negocio del azúcar y la compra-venta de prisioneros africanos para el trabajo forzado en sus plantaciones (ESTRAÑO, 2014).

\footnotetext{
2 Todas las cursivas empleadas en el texto son de la autora y se refieren a terminología de la época, categorías conceptuales que se quieren resaltar y nombres propios.
}

ESTRAÑO, Karina. Comerciantes, espias y baquianos: los esclavos criollos del Esequibo colonial. Segunda mitad del siglo XVIII. Cadernos do Lepaarq, v. XVII, n.33., p. 150-162, Jan-Jun. 2020 
Desde el siglo XVI y hasta los años 30 del XVIII, las guayanas española y holandesa permanecieron como territorios de frontera respecto a sus gobiernos coloniales, una condición que se extendería unas décadas más en el caso de las colonias de Esequibo y Demerara. Allí los intentos por desarrollar una economía de plantación fracasaron por años, entorpecidos por las trabas impuestas por la administración de la WIC. Por ello, durante más de dos centurias, la agricultura tuvo un lugar secundario y la economía se basó principalmente en el comercio de productos locales, a través de los vínculos comerciales que formaron con los indígenas de la región. Gracias a ellos, y formando también alianzas matrimoniales, los holandeses se infiltraron en una extensa red de intercambio comercial indígena, cuyo eje de comunicación principal era el amplio sistema de ríos de la selva tropical de la cuenca del Amazonas, o la Amazonía, y el escudo guayanés. Para el momento del contacto, aquél sistema estaba en pleno funcionamiento y su alcance era tal que incluso se extendía por el suroeste, hacia el Amazonas, y por el norte, hacia las islas del Caribe, hasta Mesoamérica (BIORD, 2011; 1985; ARVELO-JIMÉNEZ y BIORD, 1994; AMODIO, 1991; ARVELOJIMÉNEZ, MORALES, y BIORD, 1989; MORALES y ARVELO-JIMÉNEZ, 1981). En las cuencas del Orinoco y el Esequibo, los principales actores de esta red eran los Kari'ña ${ }^{3}$, conocidos en los textos coloniales como los Caribes, y en segundo lugar los Arawako (WHITEHEAD, 1988; CIVRIEUX, 1976).

La alianza entre holandeses y kari ñas fue un factor determinante en la resistencia indígena contra los avances de los españoles hacia el sur del Orinoco. Mientras los indígenas les proporcionaban esclavizados de otros grupos étnicos y productos de interés comercial, principalmente onoto (Bixa Orellana) y bálsamo de copaiba (Copaifera officinalis), por su parte, los flamencos aportaban alcohol, herramientas y las armas necesarias para repeler los avances de los españoles (MORALES, 1989; 1979). Al mismo tiempo, gracias al apoyo de los Kari ña, las incursiones de los holandeses hacia el territorio español fueron frecuentes, aunque su objetivo no era la ocupación territorial sino mantener alejados a los españoles para asegurar y expandir sus alianzas y redes comerciales, así como realizar exploraciones mineras. No fue sino hasta los años 20 del siglo XVIII cuando este panorama comenzó a cambiar.

Hasta entonces, distintas órdenes religiosas habían intentado controlar el sur del Orinoco sin éxito, ya que la resistencia kari ña y las dificultades para superar la carencia de comida habían obstaculizado la permanencia de los misioneros. Pero a partir de 1724, con el apoyo de escoltas armadas y de indígenas, principalmente akawayos, los capuchinos catalanes repelieron a los Kari ña y desarrollaron un sistema de hatos que aseguró el alimento y dio paso a la reducción de otros grupos indígenas, entre ellos pariagotos, barinagotos, akawayos, camaracotos y arinagotos (PERERA, 2006; CIVRIEUX, 1976). De esta manera, las misiones capuchinas se establecieron en la región que se extiende desde la serranía de Imataca hasta el río Esequibo (CIVRIEUX, 1976) y entre 1744 y 1768 controlaron los ríos Caroní, Macaruma y Yuruari, estableciendo en esa zona su principal

\footnotetext{
${ }^{3}$ Escribimos el nombre y gentilicio de los grupos indígenas mencionados en singular, siguiendo el estilo empleado en la literatura antropológica venezolana. Utilizamos mayúscula al inicio de la denominación cuando nos referimos al gentilicio o nombre de la colectividad (usualmente precedido por el arículo "los") y en minúscula cuando utilizamos el plural (p.e. grupos kari'ñas).
}

ESTRAÑO, Karina. Comerciantes, espías y baquianos: los esclavos criollos del Esequibo colonial. Segunda mitad del siglo XVIII. Cadernos do Lepaarq, v. XVII, n.33., p. 150-162, Jan-Jun. 2020 
fuente de resistencia y ataque hacia las cabeceras del Yuruari, al amparo de la serranía de Imataca. Por esos mismos años los franciscanos observantes controlaron también la región de los ríos Caura y Paragua. Por su parte, la población kari ña había disminuido considerablemente a causa de las enfermedades y las continuas guerras provocadas por los europeos (WHITEHEAD, 1988). Muchos fueron sometidos y obligados a vivir en los pueblos de misión, mientras otros se replegaron hacia las cabeceras de los ríos Mazaruni y Rupununi. Y como la principal mano de obra estaba formada por indígenas reducidos, el traslado forzado de africanos, o esclavos negros fue escaso y se redujo principalmente a los pueblos de españoles de Upata y Barceloneta, fundados principalmente con población canaria (ESTRAÑO, 2014).

Las acciones de colonización y control territorial de los españoles incrementaron las confrontaciones con los asentamientos holandeses vecinos. Desde su nombramiento como Comandante de la colonia del Esequibo en 1743, Storm van 's Gravesande enfrentó repetidos ataques contra las factorías que había construido entre el Esequibo y el Cuyuní, es decir, el territorio disputado con los españoles. Y tras varios fracasos en las expediciones mineras y comerciales, decidió replegar esfuerzos y concentrarse en el desarrollo de la agricultura. Esto significó un evidente cambio en las actividades económicas, pero las redes comerciales y de comunicación entre las colonias vecinas estaban lejos de desaparecer. En 1755, durante la Expedición de Límites al Orinoco (1754-1761), el Comisario español Eugenio Alvarado presentó un detallado informe sobre las vías de comunicación entre la Guayana española y las colonias holandesas de Esequibo y Demerara (ALVARADO, 1755b). En aquél escrito identificó cuatro formas de comunicación: 1) por vía marítima, 2) por ríos, caños y mar, 3) por tierra y ríos y 4) solamente a través de ríos. Aún bajo el control de los misioneros, el Comisario encontró entre los habitantes de las misiones relatos sobre europeos, indígenas y zambos que se desplazaban a través de los caminos de tierra y rutas fluviales, y llegaban desde el Esequibo para comerciar en las misiones. Al respecto señaló:

Este camino, que tanto por tierra como por agua consiste en once días de diligencia, es comunicable a todas las naciones de indios bárbaros que habitan las montañas de la banda del sur antemurales de la colonia de Esquivo y en especial de los caribes y al abrigo de éstos los holandeses, para hacer el comercio de los indios esclavos (que llaman poitos), las penetran continuamente hostilizando otras nacionales por todas la extensión de los montes... y por tanto no son caminos seguros para todos los individuos, sino para aquéllos que tienen sus inteligencias con los holandeses y caribes... (ALVARADO, 1755b, p. 64)

Detrás de la evidente confrontación territorial entre las colonias vecinas, ambas compartían un sistema de contrabando sobre el cual existe información dispersa en los reportes

\footnotetext{
4 (de ahora en adelante 's Gravesande).
}

ESTRAÑO, Karina. Comerciantes, espías y baquianos: los esclavos criollos del Esequibo colonial. Segunda mitad del siglo XVIII. Cadernos do Lepaarq, v. XVII, n.33., p. 150-162, Jan-Jun. 2020 
coloniales de la época (ALVARADO, 1775a, 1755b). Al respecto, resulta reveladora la negativa de los capuchinos a colaborar con las «órdenes secretas» asignadas al Comisario Alvarado, quien intentó estimular el cimarronaje o huida de esclavizados africanos desde las colonias holandesas hacia territorio español, así como facilitar armas a los rebeldes para provocar rebeliones en las colonias vecinas (RAMOS, 1946). Aquellos planes no prosperaron, en gran medida porque los capuchinos alegaron que no querían romper el acuerdo de devolver los fugitivos a sus vecinos. A pesar de que el comercio entre las dos colonias era ilegal, lo cierto es que a través de los años prosperó el intercambio, siendo los principales productos de cada colonia los más solicitados por su contraparte: azúcar, aguardiente y telas de los holandeses (ALVARADO, 1755b), y caballos, mulas, cacao, tabaco y plata de los españoles, así como productos indígenas de ambos lados (LÓPEZ DE LA PUENTE, 1789). Pero además, el desarrollo de las plantaciones en las colonias holandesas produjo una mayor demanda de mano de obra, y aunque la importación de esclavizados africanos aumentó, la compra de esclavos rojos se mantuvo por un tiempo. ¿Y quiénes estuvieron a cargo de aquellas prácticas ilegales? Algunos europeos de distintas nacionalidades participaron de esta actividad, y en el caso de la Guayana española, los indígenas de las misiones mantenían aquél comercio bajo el control, en ocasiones precario, de los capuchinos (LÓPEZ DE LA PUENTE, 1789; LA GARRIGA, 1769). Por su parte, en la colonia holandesa, la WIC utilizó un grupo que por sus habilidades resultó muy útil para los intereses de la compañía.

Ya hemos dicho que, a raíz de los avances de los capuchinos, muchos kari ñas tuvieron que replegarse hacia el territorio holandés. Una vez allí, algunos líderes en ocasiones fueron contratados como milicianos por los flamencos, y movilizaron a sus grupos para perseguir y devolver fugitivos de origen africano, que cada vez con mayor frecuencia y número huían hacia territorio español. Hay que decir, sin embargo, que esta tarea no fue permanente, sino más bien coyuntural y dependiente de los pagos en forma de regalías otorgados por los holandeses (WHITEHEAD, 1992). La mayor parte del tiempo, a pesar de que los holandeses promovieron conflictos étnicos entre indígenas, africanos y sus descendientes, los amerindios no intervenían en la vida de los asentamientos cimarrones. De hecho, con frecuencia facilitaban el paso de una colonia a otra, e incluso en ocasiones les dieron refugio en sus propias comunidades (WHITEHEAD, 1988).

Mientras tanto, un grupo cobró cada vez más importancia en las tareas encubiertas e ilegales de aquella sociedad colonial: nos referimos a los esclavos criollos, categoría aplicada entonces en las colonias española y holandesa. Nacidos de la unión entre africanos e indígenas, estos zambos, o kabugrus como también eran llamados en las colonias holandesas, fueron un numeroso grupo que se distinguió de los africanos, llamados saltwater (NETSCHER, 1988).

Como se desprende de los despachos de 's Gravesande a los directores de la Cámara zelandesa de la WIC, entre 1738 y 1772, compilados por Harris y Villiers (1911, I y II) $)^{5}$ los esclavos

\footnotetext{
5 Esta y las siguientes referencias que haga a documentos escritos por 's Gravesande, provienen de una colección de documentos obtenida por el gobierno británico cuando recibió la colonia del Esequibo en 1814. Estos fueron traducidos y recopilados en un libro que vio luz en 1911: Villiers, J.A.J. de \& Harris, C.A., Storm van 's 's Gravesande: The Rise of British Guiana; Compiled from his Despatches (1911). London, Kakluyt Society, 2 Vols. 703p (que, de ahora en adelante,
} 
criollos desempeñaron diversas tareas, como la carpintería, albañilería, panadería y la agricultura de conucos. Pero además, por sus vínculos de parentesco con los indígenas, aquellos kabugrus fueron los acompañantes preferidos en las expediciones de los caribes y holandeses. Considerados por 's Gravesande físicamente más agraciados y más inteligentes que los indígenas y los africanos (RODWAY, 1891), los criollos desarrollaron amplios conocimientos geográficos y de navegación a través del complejo sistema de ríos de la región. A la vez, asimilaron los conocimientos tradicionales y las habilidades de supervivencia de los indígenas en las intrincadas selvas del escudo guayanés. Gracias a ello se convirtieron también en intérpretes bilingües, e incluso políglotas, al aprender tanto su lengua materna como otras lenguas indígenas, además del creole que surgió en la colonia holandesa. Por ello, fueron los guías o baquianos principales durante las expediciones comerciales de los holandeses.

En aquellas tierras, el número de europeos siempre fue bajo y, por ello, la administración central tuvo que enfrentar la carencia continua de postholders, término aplicado a los militares encargados de la custodia y administración de las factorías. Aunado a esto, los comerciantes blancos estaban más interesados en hacer fortuna y regresar a Europa como hombres ricos, en lugar de formar una colonia estable en aquellas tierras calientes, conocidas como la Costa Salvaje. Además, resultaba muy difícil obligarlos a pagar los tributos de sus negocios a la WIC. Por ello, la compañía utilizó a los esclavos criollos para el comercio regional, y su actuación fue tan significativa que llegaron a ser conocidos como los comerciantes negros (WHITEHEAD, 1988). El trato diario con los indígenas estuvo en manos de aquellos sujetos subordinados, que no por ello dejaron de ser esclavizados, pero que gozaron de ciertos privilegios en comparación con los esclavizados africanos.

Los comerciantes negros desempeñaron tareas de protección territorial, exploración e invasión de las colonias vecinas, instalando sus viviendas a lo largo de los ríos y ampliando y desplazando las factorías cada vez más hacia el territorio español y portugués. Desde allí realizaban frecuentes viajes actuando como comerciantes y espías, insertos en el sistema comercial indígena al que no eran ajenos por sus vínculos familiares con los indígenas. En este contexto, los incidentes entre las dos colonias, española y holandesa, no fueron escasos. Por ejemplo, en 1758 los españoles destruyeron una factoría holandesa ubicada en el Cuyuní, y capturaron al postholder junto con un esclavo criollo, su esposa y sus hijos (STORM VAN 'S 'S GRAVESANDE, 1758a). Luego se negaron a devolver a la familia de criollos, por estar acusados de practicar el comercio con indígenas (CASTRO, 1758; STORM VAN 'S 'S GRAVESANDE, 1758B). Otro incidente ocurrió en 1761, cuando los españoles tomaron una curiara cargada de pescado cerca del río Guainia. La embarcación estaba a cargo de un criollo llamado Jan Broeck, quien había sido enviado a buscar alimento para su plantación (STORM VAN 'S 'S GRAVESANDE, 1761). Pero de todos los comerciantes negros, el más famoso de la WIC fue Tampoko, un esclavizado de confianza del propio gobernador 's Gravesande. Algunas de las tareas ejecutadas por Tampoko nos permitirán ver la importancia que tuvieron estos sujetos subordinados

citaré como Storm van's ‘s Gravesande; The Rise of British Guiana, y cuya paginación es continua). Tales referencias las presentaré por medio de un título del documento, elaborado por mí, al que acompañará la referencia bibliográfica de dicha publicación original en el repositorio documental británico del Public Record Office (de ahora en adelante, PRO). 
en el balance de las relaciones entre las colonias vecinas.

En 1765, las acciones de expansión y control de los capuchinos estaban en pleno apogeo. Ese año llegaron reportes a las colonias holandesas sobre una posible guerra que estarían promoviendo entre caribes y akawayos. Para aclarar los rumores, 's Gravesande envió a Tampoko en acciones de espionaje hacia las misiones del Yuruari (STORM VAN 'S 'S GRAVESANDE, 1767). En una carta al Rey de España, el Prefecto de las misiones capuchinas, Benito de la Garriga (1769), describió la permanencia de aquél esclavizado en sus dominios. Allí señaló que Tampoko llegó a la misiones de Guasipati, Cavallapi, y posiblemente también Avechica (WHITEHEAD, 1988), portando un pasaporte oficial de 's Gravesande y solicitando la devolución de unos esclavos rojos fugitivos. En aquella ocasión, los misioneros le permitieron hablar con los indígenas solicitados, para que escuchara de voz propia que preferían permanecer en las misiones a vivir sometidos en territorio holandés. Después de cumplir su tarea, y haciendo alarde de la excelente impresión que supuestamente había causado en él la forma de vida de los indígenas y capuchinos, Tampoko se despidió de sus anfitriones, prometiendo que regresaría con su familia y se convertiría a la religión católica (LA GARRIGA, 1769). Pero al mismo tiempo, el criollo cumplió su misión encubierta y durante su permanencia en aquellos predios encontró a un holandés que había sido apresado en el Cuyuní, quien le confirmó que en efecto, los capuchinos estaban armando a los indígenas para provocar una guerra con el propósito de avanzar hacia el este y fundar una nueva misión entre los ríos Cuyuní y Mazaruni (WHITEHEAD, 1988).

A su regreso a las colonias holandesas, y como prueba de haber cumplido su tarea, Tampoko entregó a 's Gravesande unas imágenes de santos traídas de las misiones capuchinas e informó de los planes de los misioneros (WHITEHEAD, 1988). Un año después, fue enviado nuevamente en compañía de un indígena, pero en esa ocasión ambos fueron apresados, aunque Tampoko fue rápidamente liberado para evitar confrontaciones directas con 's Gravesande (LA GARRIGA, 1769). La razón de tal acción fue que se descubrió que el criollo había llegado con dos curiaras cargadas de armas de fuego, hachas, machetes, ropas y otros objetos que fueron entregados a los indígenas, para estimular un levantamiento en las misiones. Para el Prefecto, había indicios de que los planes llevaban tiempo fraguándose, porque los indígenas de Miamo, Carapo y Guasipati habían estado construyendo canaletes, curiaras y un gran cargamento de flechas y macanas, con el pretendido argumento de ir a rescatar a los indígenas del vecino territorio holandés. Pero cuando supieron que Tampoko cayó preso pararon sus tareas, y algunos confesaron que aquél comerciante negro sería el capitán del grupo (LA GARRIGA, 1769).

Un año más tarde, en 1766, un grupo de indígenas españoles fueron detectados entre los ríos Cuyuní y Masaruni. 's Gravesande ordenó a Tampoko capturarlos y llevarlos a su presencia. Uno de ellos resultó ser un espía que anteriormente había transitado la región. Aquel hombre proporcionó nueva información sobre los planes de los Capuchinos (STORM VAN 'S 'S GRAVESANDE, 1766). Pero a pesar de toda esta labor de inteligencia, 's Gravesande no logró detener a los misioneros y en 1767 la guerra entre indígenas era ya un hecho. Tampoko reportó el ataque y destrucción caribe de una factoría ubicada en Vieja Duynemburg, cerca del Rupununi, donde vivía un hijo del criollo 
(VENEZUELA-BRITISH GUIANA BOUNDARY ARBITRATION, 1989). En ese contexto, y posiblemente alentados por los akawayos, un grupo de alrededor de cien esclavizados huyeron hacia Berbice. En respuesta, 's Gravesande reunió una avanzada indígena y la puso a cargo de Tampoko para someter a los cimarrones, con la orden de no atacar a los akawayos. El criollo regresó, trayendo consigo varias manos que supuestamente había cortado de los cadáveres de los cimarrones, reportando que había matado al líder. Pero al poco tiempo hubo reportes que señalaban que Tampoko había mentido y que las manos entregadas eran de indígenas. 's Gravesande reaccionó con sorpresa, ordenó apresar al criollo e iniciar una investigación, pero antes de llegar a su presencia, el esclavizado se suicidó (WHITEHEAD, 1988).

A pesar de las inesperadas circunstancias de la muerte, en su relación epistolar con la WIC, el Comandante del Esequibo no dejó de manifestar sus dudas sobre la culpabilidad de aquel criollo que durante largos años había prestado un servicio tan valioso a sus intereses (STORM VAN 'S 'S GRAVESANDE, 1769a). En 1769, Storm van's 's Gravesande declaró que el Cuyuní había sido completamente controlado por los españoles, quienes tomaron el río Barima y negociaban con los cimarrones del Esequibo y Demerara para engrosar sus milicias (STORM VAN 'S 'S GRAVESANDE, 1769b). En 1772 el Comandante sería relevado de su cargo y se retiraría para culminar su vida en su plantación privada, ubicada en Demerara (RODWAY, 1891). Lo que ocurrió después entre las dos colonias forma una profunda interrogante para la investigación histórica y antropológica, sobre todo cuando nos preguntamos por los movimientos de fugitivos tanto indígenas como africanos y afrodescendientes que se produjeron entre el Orinoco y el Esequibo durante la Guerra de la Independencia en Venezuela, por un lado, y el largo proceso de ocupación colonial de Inglaterra en lo que hoy es el territorio guyanés, por el otro.

\section{PALABRAS FINALES}

Con la destrucción de las misiones capuchinas en Venezuela y el cambio radical de gobierno en la otrora colonia holandesa, aquellas redes comerciales fueron sometidas a una nueva y gran inflexión histórica. ¿Habrán desaparecido como consecuencia de los profundos cambios vividos en las regiones vecinas? ¿O acaso sobrevivieron, transformándose una y otra vez, sosteniendo el dinámico intercambio de productos, de información y de vida? Tal vez fueron destruidas. Y tal vez, a través del tiempo, han surgido otras redes y otros actores, con nuevas historias que sin embargo tienen su asiento en aquellas historias antiguas, quizás olvidadas de hombres y mujeres que de esclavizados pasaron a ser campesinos, peones y figuras similares, ¿libres? La libertad en contextos de dominación colonial y postcolonial es siempre una figura escurridiza, un valor de realidad contingente más que permanente. Pero, en cualquier situación, los habitantes del Esequibo hoy en día siguen siendo pescadores, agricultores, pequeños comerciantes, mineros. En fin, sujetos subalternos cuyas vidas transcurren a través de los ríos guayaneses, atados en cierta forma a la lógica del poder, pero siempre en movimiento. Esas historias sobre nuevas y actuales redes subalternas esperan a ser contadas por sus protagonistas, o tal vez nosotros esperamos escucharlas para conocerlos y finalmente, conocernos.

ESTRAÑO, Karina. Comerciantes, espias y baquianos: los esclavos criollos del Esequibo colonial. Segunda mitad del siglo XVIII. Cadernos do Lepaarq, v. XVII, n.33., p. 150-162, Jan-Jun. 2020 


\section{REFERENCIAS}

ALVARADO, Eugenio. Modo religioso y económico del vivir los padres, granjerías del común de las misones como del particular de los padres, indios y demás agregaciones a ellas, por D. Eugenio de Alvarado (Hato de la Divina Pastora, 20 de Abril 1755)» En CARROCERA, Buenaventura, Misión de los capuchinos en Guayana. Caracas: Academia Nacional de la Historia, v. I, 1979 [1755a], p. 338-351.

ALVARADO, Eugenio. Relación sobre la colonia holandesa de Esequibo. En LUCENA, Manuel (1999). Viajes a la Guayana ilustrada. El hombre y su territorio. Caracas: Banco Provincial, 1999 [1755b], p. 55-58.

AMODIO, Emanuele. Relaciones Interétnicas en el Caribe Indígena. Una reconstrucción a partir de los primeros testimonios europeos, Revista de Indias, v. 51, №193, p. 571-606, 1991.

ARELLANO, Fernando. Una introducción a la Venezuela prehispánica. Caracas: Universidad Católica Andrés Bello, 1982.

ARVELO-JIMÉNEZ, Nelly, y BIORD, Horacio. The impact of conquest on contemporary indigenous peoples of the Guiana Shield: the system of Orinoco regional interdependence. En ROOSEVELT, Ana (Coord.). Amazonian Indians from prehistory to the present anthropological perspectives. Tucson/London: The University of Arizona Press, p. 55-78, 1994.

ARVELO-JIMÉNEZ, Nelly, MORALES, Filadelfo y BIORD, Horacio. Repensando la historia del Orinoco. Revista de Antropología, Bogotá, v. 1-2, p. 153-174, 1989.

BIORD, Horacio. Del río al mar: sistemas interétnicos del Orinoco y la Costa Orinoco Caribe en la época colonial. Revista Nacional de Cultura, Caracas, №.338, p. 44-58, 2011.

BIORD, Horacio. El contexto multilingüe del sistema de interdependencia regional del Orinoco. Antropológica, Caracas, 63-64, p. 83-101, 1985.

BRITO, Federico. El problema tierra y esclavos en la historia de Venezuela. Caracas: Universidad Central de Venezuela, 1996.

BRITO, Federico. Historia económica y social de Venezuela. Caracas: Universidad Central de Venezuela, v. I, 1993.

CASTRO, Nicolás. [Inclosure II.] Don Nicolás de Castro to the Director-General of Essequibo, Cumaná, November 10, 1758. En HARRIS, C.A. y VILLIERS, J.A.J. de, Storm van 's 's Gravesande. The rise of British Guiana; Compiled from his Despatches. London: Hakluyt Society, 2 Vols, 703 págs. (de ahora en adelante Storm van's 's Gravesande; The Rise of British Guiana), v. I, p. 365-366, 1911 [1758].

CIVRIEUX, Marc. Los caribes y la conquista de la Guayana española: etnohistoria Kari'ña. Caracas: Instituto de Investigaciones Históricas, Facultad de Humanidades y Educación, Universidad Católica Andrés Bello, 1976. 
ESTRAÑO, Karina. Pueblos Mixtos y “de Españoles” al sur del Orinoco: La participación de los zambos, mulatos, cimarrones y otras gentes de color en el poblamiento y control territorial de la Guayana española. Segunda mitad del siglo XVIII. Boletín Antropológico. Universidad de los Andes, Museo Arqueológico, Mérida, Venezuela. Nㅜ95, p. 165-192, 2014.

GOMES, Flavio. Etnogénesis en las fronteras entre Brasil, Surinam y Guayana Francesa, siglos XVII-XX: más aproximaciones. Antíteses, Brasil, v. 4, n8, p. 631-644, 2011.

GOMES, Flavio. Other Black Atlantic borders: escape routes, ýmocambosý, and fears of sedition in Brazil and French Guiana (eighteenth to nineteenth centuries). New West Indian Guide, v. 77, No3-4, p. 253-287, 2003.

KLOOSTER, Wim y OOSTINDIE, Gert. El Caribe holandés en la época de la esclavitud. Anuario de Estudios Americanos, Sevilla, v. 51, n², p. 233-259, 1994.

LA GARRIGA, Fray Benito. Informe del P. Prefecto Benito de La Garriga al rey, manifestándole la situación de la misión en relación sobre todo con los holandeses de Esquivo. En CARROCERA, Misión de los capuchinos en Guayana. Caracas: Academia Nacional de la Historia, v. II, p. 99-104, 1979 [1769].

LÓPEZ DE LA PUENTE, Antonio. Diario de mi viaje al reconocimiento del río Cuyuní, que desagua en el Esequibo. En LUCENA, Viajes a la Guayana ilustrada, Caracas: Banco Provincial, p. 222-227, 1999 [1789].

MORALES, Filadelfo. Del morichal a la sabana. Caracas: Universidad Central de Venezuela. Facultad de Ciencias Económicas y Sociales. Escuela de Sociología y Antropología, 1989.

MORALES, Filadelfo. Reconstrucción etnohistórica de los Kari'ña de los siglos XVI y XVII, Tesis (Maestría en Ciencias, Mención Antropología) Centro de Antropología, Instituto Venezolano de Investigaciones Científicas, Caracas, 1979.

MORALES, Filadelfo y ARVELO-JIMÉNEZ, Nelly. Hacia un modelo de estructura social caribe. América Indígena, México, D.F., p. 603-626, 1981.

PERERA, Miguel. El Orinoco domeñado. Frontera y límite. Caracas: Universidad Central de Venezuela/CDCH/FACES, 2006.

RAMOS, Demetrio. El Tratado de Límites de 1750 y la expedición de Iturriaga al Orinoco. Caracas: Academia Nacional de la Historia, 1946.

RODWAY, James. History of british Guiana, from the year 1668 to the present time. Georgetown, Demerara: J. Thompson, v . 1, 1981.

STORM VAN 'S 'S GRAVESANDE, Laurens. "PRO, 470/128" [sin título: Despatche write to the Directors of the Zeeland Chamber of The West India Company, September 9, 1758]. En Storm van's 's Gravesande, The Rise of British Guiana, v. I, p. 356-359, 1758a

STORM VAN 'S 'S GRAVESANDE, Laurens. [Inclosure I.] Director-General Essequibe, to the Comandant of Guayana, September, 30, 1758]. En Storm van's 's Gravesande; The Rise of British 
Guiana, vol. I, p. 363-365, 1758b.

STORM VAN 'S 'S GRAVESANDE, Laurens. PRO, 471/44. Sin título: Despatche write to the Directors of the Zeeland Chamber of The West India Company, August 12, 1761. En Storm van's 's Gravesande; The Rise of British Guiana, v. II, p. 388-389, 1761.

STORM VAN 'S 'S GRAVESANDE, Laurens. PRO, 472/169 January 18, 1766. Extracts. En Storm van's 's Gravesande; The Rise of British Guiana, v. II, p. 496-500, 1766.

STORM VAN 'S 'S GRAVESANDE, Laurens. PRO, 473/37 March, 20, 1727 (Extracts). En Storm van's 's Gravesande; The Rise of British Guiana, v. II, p. 528-54, 1767.

STORM VAN 'S 'S GRAVESANDE, Laurens. PRO, 474/195 February, 21, 1769 (Extracts). En Storm van's 's Gravesande; The Rise of British Guiana, v. II, p. 596-600, 1769a.

STORM VAN 'S 'S GRAVESANDE, Laurens. PRO, 474/229 May, 12, 1769 (Extracts). En Storm van's 's Gravesande; The Rise of British Guiana, vol. II, págs. 612-615, 1769b.

TURNER, Jackson. The frontier in american history. New York, Henry Broet and Company, 1953.

VENEZUELA-BRITISH GUIANA BOUNDARY ARBITRATION. The case of the United States of Venezuela before the Tribunal of arbitration to convene at Paris under the provisions of the treaty. New York: The Evening post, V. I, disponible en <https://archive.org/details/ venezuelabritis01venegoog.> 1989 Último acceso en 19/11/2019.

WHITEHEAD, Neil. Lords of the tiger spirits. Dordrecht, Holanda: Foris Publications Holland, 1988.

WHITEHEAD, Neil. Tribes make states and states make tribes: Warfare and the creation of colonial tribes in northeastern south America. En FERGUSON, Brian y WHITEHEAD, Neil (Coord.) War in the tribal zone: expanding satates an indigenous warfare. Santa Fe: School of American Research Press, págs. 127-150, 1992. 